\title{
Lecture-free Teaching for Systems Analysis: An Action Research Study
}

\author{
Gary Griffiths and Briony J Oates \\ University of Teesside, Middlesbrough, United Kingdom
}

\section{G.Griffiths@tees.ac.uk B.J.Oates@tees.ac.uk}

\begin{abstract}
This paper discusses experiences in moving to lecture-free teaching for a systems analysis module taught on-campus. It describes the action research approach and the context for the module. It discusses the learning materials provided as an alternative to lectures, including the description of a website in some detail. The initial lecture- free teaching approach is explained and how changes to that practice were made during the operation of the module. Student feedback by questionnaire is analysed, concentrating on the learning materials, the teaching approach and the advantages and disadvantages. Staff reflections and lessons learnt are considered under the same headings. Conclusions are drawn and further work proposed.
\end{abstract}

Key words: systems analysis, student-centred learning, action research, teaching styles

\section{Introduction and Rationale}

Of all instructional methods, lecturing is thought to be the most common and yet the least effective (Felder, 1992). It has been shown that immediately after a lecture students recalled $70 \%$ of the information presented in the first ten minutes and only $20 \%$ of that from the last ten minutes (McKeachie, 1986). The research of Edgar Dale found that levels of effectiveness in learning are directly related to the participation of the student. His cone shaped model (the 'Cone of Experience') represents the retention rates in students for different methods of presenting course material (Dale, 1969). This shows that students tend to retain $10 \%$ of what they read, $20 \%$ of what they hear and $30 \%$ of what they see. However, learners tend to retain much more of the material when their engagement with it is high, that is, when they are active learners rather than passive members of an audience (Dale, 1969; Bonwell \& Eison, 1991). The rise in off-campus, distance learning has meant academics have had to find replacements for conventional teaching methods such as the lecture (e.g. Gibson, 1998; Khan, 1997), but for on-campus learning the traditional lecture is still very common.

However, because small group teaching is often more enjoyable and rewarding for staff than lecturing, and there are many good learning materials available in the subject area that we teach (systems analysis), we felt a strong impetus to move to lecture-free teaching even for on-campus students. We have been aware for many years of a tendency to 'spoon feed' science students and wanted to try to get away

Material published as part of these proceedings, either on-line or in print, is copyrighted by Informing Science. Permission to make digital or paper copy of part or all of these works for personal or classroom use is granted without fee provided that the copies are not made or distributed for prof it or commercial advantage AND that copies 1) bear this notice in full and 2) give the full citation on the first page. It is permissible to abstract these works so long as credit is given. To copy in all other cases or to republish or to post on a server or to redistribute to lists requires specific permission from the publisher at Publisher@InformingScience.org from that (for the students' sake) and put the st udents in direct contact with learning mater ials without us acting as translator or intermediary.

This paper discusses our experiences in moving to lecture-free teaching for a systems analysis module delivered on-campus. It can be seen as an action research study of lecture-free teaching. We explain the teaching and learning material that we 
Lecture-free Teaching

provided for students, the approach that we initially adopted, how it was changed in the light of our experiences, the reactions from the students, the lessons learned and our recommendations for future work.

\section{Research Approach}

The study followed an action research approach. Action research involves researchers planning and evaluating their own practice, where the results are fed back into the practice to modify it, leading to a further round of practice and evaluation, and so on. The most prevalent description (Susman \& Evered, 1978) identifies a five-phase iterative cycle: 1) diagnosing 2) action planning, 3) action taking, 4) evaluating and 5) specifying learning. This can be seen as an 'ideal type'- in practice the action research method will vary depending on the application. It has been used in, for example, organisational development (Van Eyende \& Bledsoe, 1990), nursing (Abbott \& Sapsford, 1998), education (Zuber-Skerritt, 1992; 1996) and our own field of information systems (Avison et al, 1999; Baskerville \& Wood-Harper, 1996; IT\&P, 2001). In the study reported here we followed an action research approach in that we ide ntified drawbacks of a teaching approach using lectures, planned how we could teach a systems analysis and design module without lectures, carried out our plan, reflected on it and on the students' responses to it, modified it, carried out our modified plan and reflected upon what could be learnt from our experience.

\section{The Module}

We were allocated an on-campus module, 'Development of IT Systems', on the MSc in Information Technology course. There were forty students on this masters 'conversion' course, all of whom had graduated in other disciplines e.g. business studies, history or textiles. Most of the students were studying full-time, but three were part-time. Given the relatively small number of students (for a UK university), and their likely maturity, this seemed an ideal opportunity to try out lecture-free teaching. The module largely involved developing the students' skills in analy sing problems and developing systems analysis models such as data flow diagrams and entity relationship diagrams (for an overview of the topics covered see Figure 1 below). The practical, skills-based nature of the module indicated that lecturefree teaching could be an appropriate approach, allowing the students to concentrate on 'practising how', rather then 'listening how'.

\section{Learning Materials}

There is a wealth of good teaching materials in systems analysis and design. Many have been developed at our own university over a number of years, with the aid of public funding. The main learning materials for the module were:

- A textbook in the subject (Griffiths, 1998).

- A web site we developed to support the module (which we discuss in greater detail below).

- A set of videos which we and our colleagues had previously developed with funding from the government's Department of Trade and Industry (Griffiths \& Lockyer, 1992).

- A software tool, ASCENT (Lockyer \& Griffiths, 1989), available to the students to support their diagramming. This CASE (Computer-Aided Software Engineering) tool was developed with our university colleagues and has been used with many students at home and abroad over a number of years. It enables the students to 'draw' on a computer screen the main diagrams used in systems analysis; checks that the diagrams follow the appropriate 'rules'; and runs consistency and co mpleteness checks on the diagrams. 


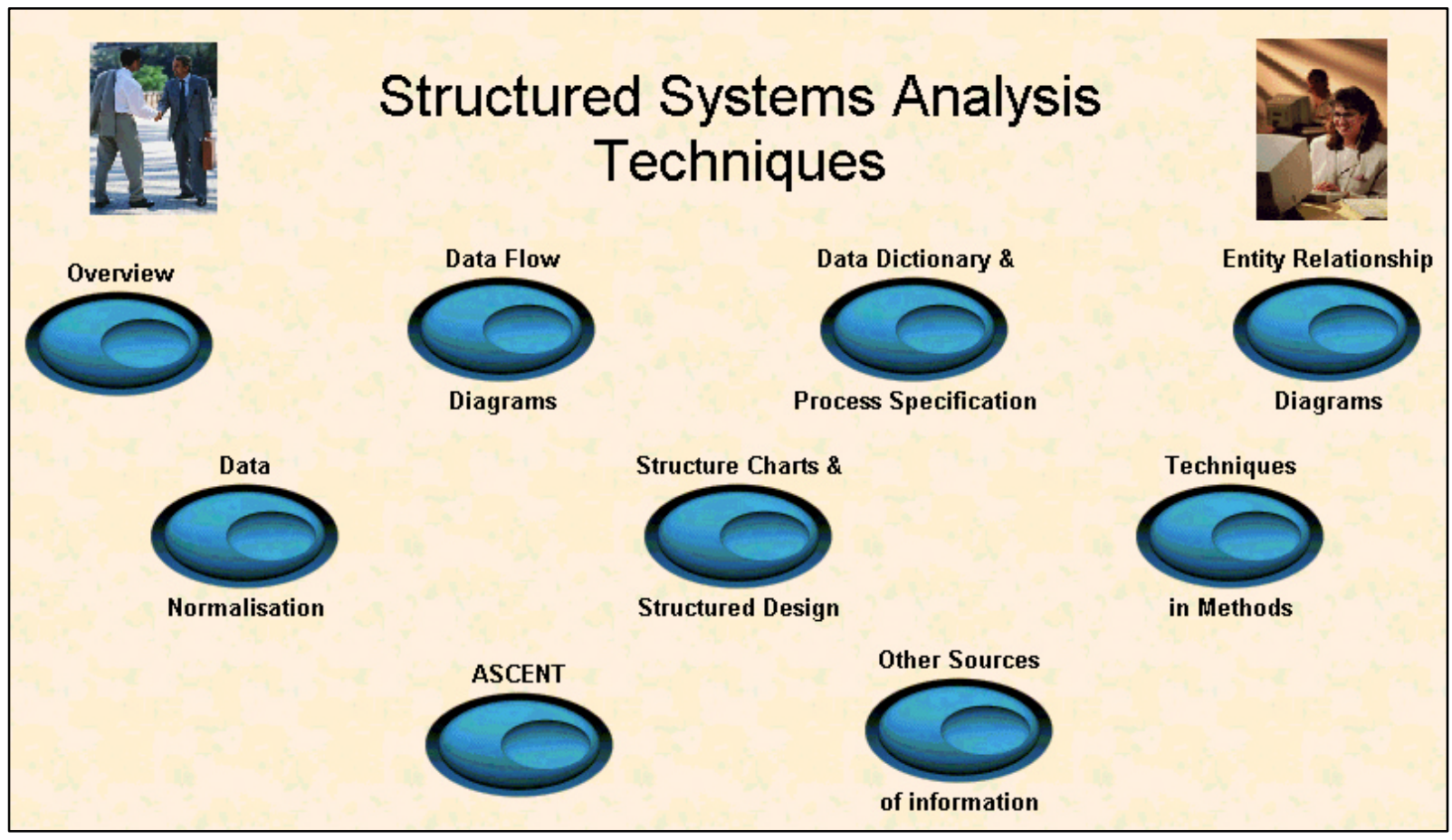

Figure 1: Top level of web site

- Courseware on systems analysis (W.I.S.D.E.N.) that emerged from a national Teaching and Leaming Technology Programme (TLTP) project in which our university was a partner.

- A selection of other recommended books and web sites (e.g. Dennis \& Wixom, 2000; Robinson \& Prior, 1995; Yourdon, 1989; Avison \& Fitzgerald, 1995; Wiley, 2002).

It is useful to give a little more detail about the web site here, so that the student feedback described below can be better understood. The web site is delivered via our department's intranet. At the top level, it shows the various techniques that are covered, such as data flow diagrams and the data dictionary (see Figure 1).

At the next level down a standard pattern is followed for each technique (see Figure 2).

First, the theory is introduced. This is usually done by a video clip, but sometimes text is used if video is not appropriate. The video clips were captured and edited from the set of videos referred to above. Next, a worked example is 'walked through' (see below) and the student is set a similar exercise to do. Then a solution to the exercise is 'walked through' and finally a summary or conclusion about the topic is given.

Walkthroughs are a technique that emerged from our previous research (Lockyer \& Hoggarth, 1996). Often in systems analysis, students are required to develop diagrams to model the information provided in a piece of text. Walkthroughs show dynamically the gradual build up of a diagram, highlighting parts of the text that caused particular diagram elements to be drawn, and giving comments about the new elements in arrowed bubbles on the diagram itself (see Figure 3). They can be developed directly from ASCENT, or other drawing tools can be used to develop walkthroughs in the same style. Both methods were used in the creation of walkthroughs for the web site. 
Home

DFD Home

\section{Current Logical DFDs}

Drawing Conventions

Example 2.1 X

$>$ Exercise 2.1 Problem Statement

$>$ Exercise 2.1 Solution $\lambda$

$>$ Common Mistakes

Summary of Important Points

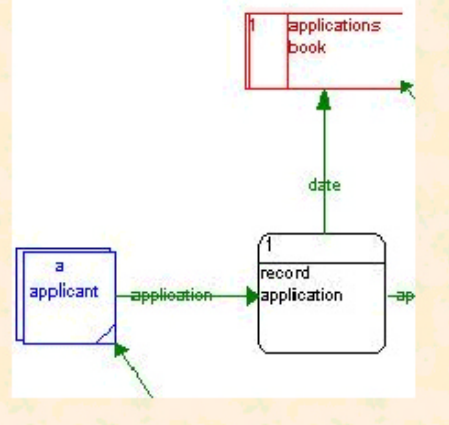

Figure 2: Second level of web site

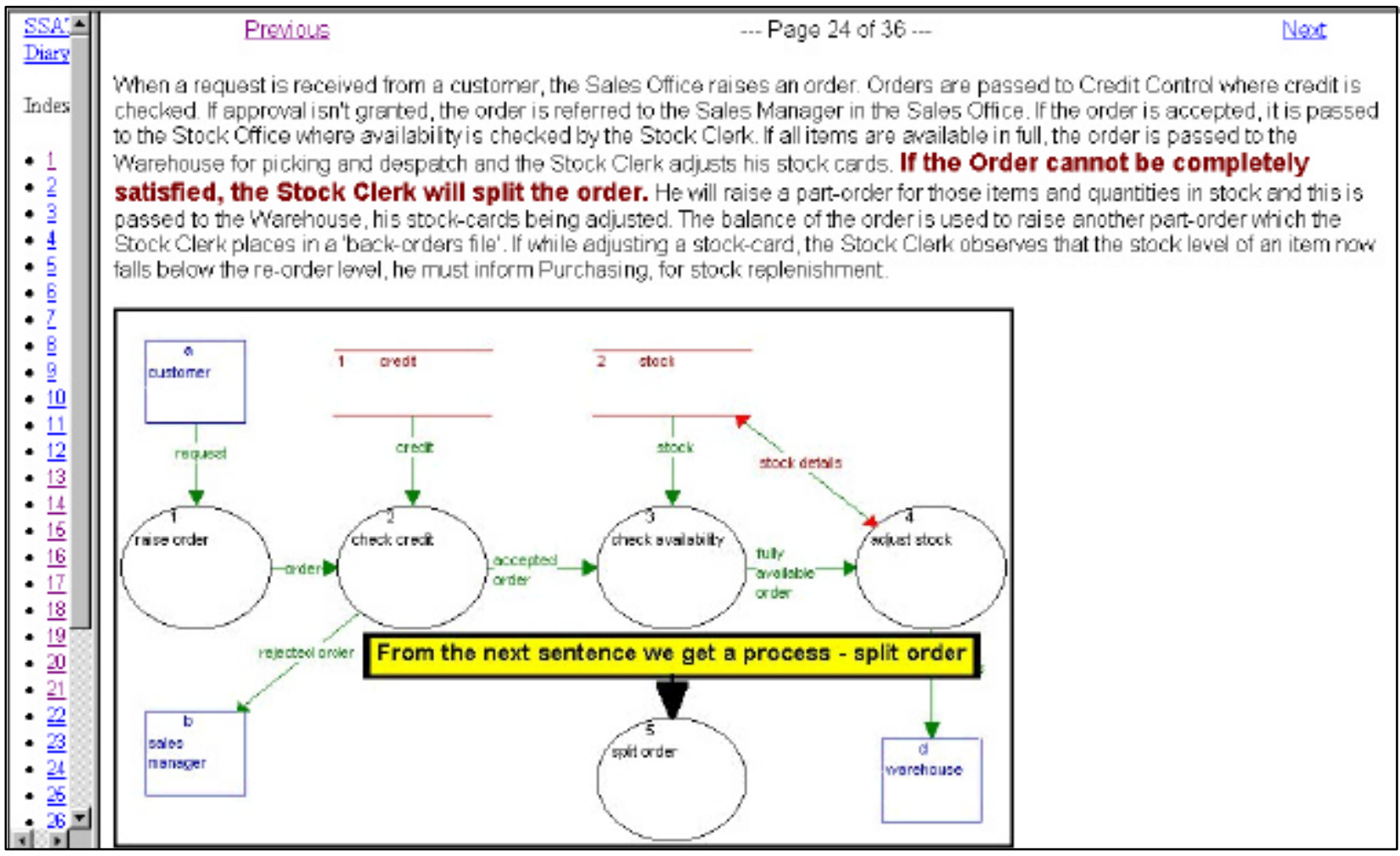

Figure 3: A walkthrough 


\section{Initial Teaching Approach}

Our initial teaching approach was described in detail to the students in the first week of their course, via an introductory meeting. They were told that no lectures would be delivered to support the course, but many learning materials were available. They were given the choice of using the book, web site or videos (or any combination) as primary support for their learning, and these were described and demonstrated. The students were also told about the secondary sources available (other books, web sites, courseware).

The weekly learning pattern was clearly explained. The material had been divided up into weekly chunks of theory and an associated exercise. The primary sources were to be used to look at the theory and worked example before attempting each exercise. If there were difficulties at this stage, solutions to the exercises were available (in all primary sources). We would also be available for consultation in our offices in a weekly two-hour timetabled slot (where normally a lecture would have taken place) and could be contacted via e-mail at other times.

The students were also expected to attend a weekly one-hour lab-based practical session where a tutor would be available. It was stressed that attendance at the se practical sessions was very important. They would be used:

- to give feedback to each student on their attempt at the exercise,

- to give an extra, optional exercise,

- to give direction for the next week, and

- for the students to get practice in using the ASCENT software tool while help was available.

The students' timetable also included a further weekly, one-hour, unsupported lab-based practical session, where a tutor would not be in attendance and where students could work on their own or with fellow studerts, using the ASCENT software tool as necessary. Following the weekly contact with their tutors, students were expected to look at any summaries or conclusions about the topic before repeating the pattern for the next week's topic.

\section{Changes to Practice during Module Operation}

Reflections during our practice meant that some necessary changes to the module's working soon became apparent. The students were split into two groups of twenty for practicals. It was obvious early on that this was too large a group to see in the manner that we had planned. Bas ically there were too many students to get round to give detailed individual feedback on their systems analysis work (which we saw as vital). To overcome this we split the class into four groups of ten. In theory this meant that more teaching was now being allocated to the module. In practice there was little difference from a 'normal' module as we were not often consulted in our offices during 'lecture' slots.

It is worth noting that, even with a traditional lecture-based approach, it would have been just as difficult to cope with a group of twenty in a practical session. We had considered the use of study groups where students operate in groups of four or five to study, meeting outside of formal contact to discus s the work and support each other, and meeting the lecturer as a group. We did not proceed with this because of student resistance (mostly because they did not know each other at the start of the module), but it remains a possibility for the future (and is discussed further below).

The other change that was apparent very quickly was that not all students were going at the pace that we had set. A few were going faster, most were going at the set pace, but a significant minority was going slower. Reasons for this included students with illness problems, part-time students with work-based pressures, students who learnt more slowly and students choosing to devote more energy at that time to 
other parts of their course. It seemed to us that this was entirely consistent with the student-centred learning approach that we were taking. We therefore told the students that it was not necessary to go at the pace that we had set, and that a better philosophy might be that all of the work had to be finished by the time the assessment started. Actually, many students did continue to go at the pace that we had set at the start, but other students became more relaxed and open about their progress and difficulties.

\section{Student Feedback}

Towards the end of the module, students were asked to complete a questionnaire and return it to us anonymously (see Appendix). We stressed that we wanted them to tell us the truth and not just what they thought we wanted to hear, and 32 of the 40 were returned - a good response rate. On the questio nnaire we asked questions about the learning materials, the web site, the lecture-free teaching approach and the advantages and disadvantages that the students perceived with such an approach. Their responses are discussed below.

\section{Student feedback: Learning Materials}

All students used the book and the web site. We asked them to estimate the percentage that they used each. Only two students used the web site more than the book. Of the remainder, the split varied from $50 / 50$ to $90 / 10$ (book/website), with an average roughly at 70/30.

The main reason cited for using the book was availability and access. Once they had bought the book or borrowed it from the library, they could work from it anywhere. Most students used the book for the theoretical introduction to a topic, the examples and the summaries.

Most students used the web site for the walkthroughs. They found that style of walking through a worked example or exercise solution much better than a book where you often needed to be flipping pages to try to marry up the text and the figures. All students except one said that they liked the walkthroughs and could easily navigate the web site.

Only four people used the videos. The main reason cited was lack of availability. Only two copies of the video series were available to the students: one in the department and one in the University library. The difficulties in obtaining the videos at the time that they wanted and then finding somewhere to look at them were too great for most. Also, the videos left them with no hard copy for future reference.

Almost half of the students (15) did not look at the video clips on the web site at all. This was because of practical problems. Some forgot or did not have headphones to listen to the sound in the laboratories. Some wanted to watch the video clips at home and were put off because the clips were embedded in the web site in such a way that they downloaded rather than streamed. This was acceptable on an intranet where the clips downloaded in seconds, but at home it would have taken minutes to download a single clip and it was not worth the wait. There is no technical problem with streaming the video clips, but it does mean more development time. It is an improvement to the web site that has now been made for future classes.

Of the students that did look at the video clips, 8 liked them and 9 did not. Some liked the variation, while others criticised the image or audio quality (which is unfortunately inevitable with current technology).

We wanted to know whether students would have liked a 'bookmark' on the web site, i.e. something that indicated where they should be up to at that point in time. However, we made a classic mistake in the questionnaire of asking two questions at once 'Did you usually know what to do next from week to week or would you have liked a bookmark on the site?' Five students just answered 'Yes' to this, which is difficult to interpret. However, most gave more detail and it was clear that two thirds did know what 
to do. Twelve said that they would have liked a bookmark, although several said that they did not mind either way. Three said that they would not have liked a bookmark as it would have put too much pressure on them.

\section{Student feedback: Teaching Approach}

Twenty-five students said that they preferred the student centred approach that we had used to the traditional approach based on lectures and tutorials that they had encountered in their earlier studies and elsewhere on the MSc course. Five students said that they would have preferred the traditional approach Seven students said that they would have been happier with a student centred approach if it had included at least some lectures.

\section{Student feedback: Advantages and Disadvantages}

The main advantage that the students saw in this alternative approach was auto nomy. They liked the freedom to go at their own pace, in their own time and at their own place. They also felt that it taught them self-reliance, particularly time management and motivation, which they saw as important in the outside world. Two students commented that the approach 'made them feel like postgraduate students', which was pleasing, and three students commented that it was hard to concentrate and too easy to switch off in traditional lectures.

Several students commented that they thought that they had come to a better understanding of the material by approaching it in the way that they did. They also thought that attempting some practical work before coming to the practical allowed them to concentrate on the problem areas and difficulties with us. This was contrasted with the approach where they came to the practical having done nothing and had just worked out what they needed help with when the practical was ending.

There were also some disadvantages with the approach that were raised by students. While some students raised motivation as an advantage, it was also raised as a disadvantage by others, or even by the same students. We talked to a few of the students informally about this afterwards. They said that they thought self-reliance was important, that they should learn to motivate the mselves and that they were glad that they had the opportunity, but that it was very difficult and in some ways wished that someone else had been doing it for them. Students also felt that there was less interaction and feedback because they were only in a room with us once a week. Three said that they felt 'abandoned' or 'lost', particularly at the start of the module.

\section{Reflections and Lessons Learnt}

The module was assessed by a one-week full-time case study where the students worked in groups on a practical systems analysis problem. In the assessment we found that students demonstrated a higher level of skill and understanding using a student centred approach than they might have been expected to reach using the traditional approach that we have used before. In fact, the mean for this group of students was higher than the previous year by $5 \%$. However, we suspected that this was a particularly good cohort of students. This has been borne out subsequently in the following year when the same lecturefree teaching approach was used, but the module mean fell by 5\%. It is therefore important to consider whether the change to lecture-free teaching was worthwhile. Below we discuss our own reflections concerning the learning materials, teaching approach and the advantages and disadvantages of this approach. 


\section{Learning Materials}

The amount of time needed to develop learning materials should not be underestimated. We have obviously spent an enormous amount of time writing a book, making a series of videos etc. in previous years. We also spent about two months part time developing the web site to support the module, although about half of that time was spent in capturing and editing video clips and it is not clear that was time well spent, given their poor student use and evaluation. So, it would be easy to draw the conclusion that because of the effort involved in developing the learning materials it is not a viable approach. We do not think that this is a valid conclusion, though, for two reasons. First, the learning materials can be used for a number of different modules and for several years with minor maintenance. Second, it is not necessary to develop a range of learning materials with this degree of sophistication to support the approach. It could work just as well with a set of good, word processed lecture notes.

Most universities have people dedicated to producing learning materials (other than lecturers). Personal observations during visits to various UK universities suggest that this seems to be most successful where the staff are located in the academic unit rather than in the university central services. If lecturers from the academic unit are seconded to this activity, they obviously have some understanding of the subject matter and context in which the teaching takes place, and are more committed to producing materials for their direct colleagues. We would welcome more formal research into the most effective means of providing this support.

\section{Teaching Approach}

University administrators often see the use of student centred learning and lecture-free approaches as means of reducing staff-student contact time. However, as mentioned above, in the end our approach did not actually save us any contact time. Instead of the two lectures, two tutorials that we would have done normally, we ended up doing no lectures and four tutorials. We certainly felt, however, that the contact time was more productive and we enjoyed giving the module in this way much more than previously. As we discussed in the previous section, the majority of the students also preferred this approach to lecturebased teaching, and recognised that they had developed self-reliance, particularly time management and motivation.

\section{Advantages and Disadvantages}

This approach might not work for all people and all situations. In many ways teaching style is a personal issue and it is difficult to make a style work that you are not committed to or do not feel comfortable with. However, we do feel that student centred approaches should be used more. We would all say that we are trying to develop autonomous and independent learners, but often our rhetoric does not match our practice. Certainly on courses that we have taught on, the staple diet has been traditional lectures and practicals through all years of the course. It is often only in small amounts of case study and project work that the learner moves away from this model. It is likely that this is a familiar model across many science courses. We would like to see teaching methods monitored across courses and an attempt made to introduce at least some student centred learning in the first year of undergraduate courses. Ideally this would increase throughout the course.

Working with practical groups of twenty is not conducive to student centred approaches. In this case we were able to reduce the practical groups to ten students, by utilising the academics' time that would normally have been allocated to lectures. However, as class sizes increase, in line with our government's desire to increase university participation but without a proportional increase in resources, practical groups of less than twenty are unlikely to be possible. Students expect and need regular contact with their tutors. As we discussed above, some of our students felt that there was less interaction and feedback because they were only in a room with us once a week, and some felt 'abandoned' or 'lost' at the 
start of the module. We have to recognise that a lecture to a large number of students is cheaper than a series of practical sessions with a dozen or so students, and does provide students with the perception of contact with the academic staff. We therefore recognise a tension between the desire to expand university participation and a desire to use innovative teaching approaches based on student-centred active learning - perhaps best summed up as efficiency versus effectiveness.

One possible response to address the issue of some students feeling there was less interaction and feeling 'abandoned' at the start of the module would be to have the students in study groups. Students would operate in groups of four or five to study, meeting outside of formal contact to discuss the work and support each other, and would then meet the lecturer as a group. Dale's Cone of Learning (Dale, 1969) suggests that such 'peer tutoring' enables the most student retention of any learning approach. As we mentioned earlier, our students resisted this approach, mostly because they did not know each other at the start of the module. However, we feel the students might be more receptive to the idea if they were given structured opportunities at the beginning of the module to form such study groups. This would also help prepare them for the end-assessment, which is based on group work. Our current approach did not give them the opportunity to form well functioning groups prior to the assessment.

If students were stuck on a particular exercise, model answers were available in the book and videos and on the website. Although our intention was to provide support to the students, we realise now that it could be too tempting for students to read the answer without properly trying to find their own solution. As Dale showed (Dale, 1969), reading is far less effective for student learning than experiential work. A better approach would be to make the model solutions available only after the students have had sufficient time to find their own solutions. This could be done by either uploading a solution to the website after a week or two, or using a computer-based learning environment such as Blackboard, which allows the tutor to set a date from when material can be publicly viewed.

\section{Conclusions and Further Work}

This paper has discussed our action research into our own practice as academics when we moved to lecture-free teaching for a systems analysis module. We have explained the teaching and learning material that we provided for students, the approach that we initially adopted, how it was changed in the light of our experiences, the reactions from the students, the lessons learned and our recommendations for future work.

Overall we feel that the approach was successful. In the next cycle of our continuing action research into this approach we shall try to incorporate study groups, as well as make improvements to the web site.

The approach was successful in a specialised situation: a small class of mature, well-motivated students developing practical skills. But will it work with large classes of undergraduate or sub-degree programme students in their first year? We intend to use this approach with BSc Year 1 students in future to start to answer that question.

The module was concerned with the development of practical problem analysis and modelling skills. We see no overarching reason why the approach should not also work for a knowledge-based module. After all, arts undergraduates have been given outline lectures and sent away to do reading before coming back to a tutorial to discuss it for many years. However, this does require that all the arts studerts work at the same pace each week. As we discovered, students are often unable to work at the same pace as their peers for quite legitimate reasons, and as more of them are forced to take up part-time work to help fund their studies, this situation is likely to worsen. There is therefore a need to find a balance between setting a pace to guide students while also supporting learner autonomy and without adding to the pressures students already face. 
We started this paper by relating that lecturing is thought to be the most common and yet the least effective of all instructional methods (Felder, 1992). We have experimented with lecture-free teaching and have found that learning outcomes can be achieved in a more fulfilling and beneficial way for staff and students.

\section{References}

Abbott, P., \& Sapsford, R. (1998). Research methods for nursing and the caring professions. Buckingham: Open University Press.

Avison, D., Lau, F., Myers, M., \& Nielsen, P. A. (1999). Action research. Communications of the ACM, 42(1), 94-97.

Avison, D. E., \& Fitzgerald, G. (1995). Information systems development: Methodologies, techniques and tools (2nd ed.). London; New York: McGraw-Hill.

Baskerville, R. L., \& Wood-Harper, A. T. (1996). A critical perspective on action research as a method for information systems research. Journal of Information Technology, 11, 235-246.

Bonwell, C. C., \& Eison, J. A. (1991). Active learning: Creating excitement in the classroom: ASHE-ERIC Higher Education Report No. 1, George Washington University.

Dale, E (1969). Audio visual methods in teaching (3rd ed.). New York: Holt, Rinehart, Winston.

Dennis, A., \& Wixom, B. H. (2000). Systems analysis and design. Chichester: Wiley.

Felder, R. (1992). How about a quick one? Chemical Engineering Education, 26(1), 18-19.

Gibson, C. C. (1998). Distance learners in higher education: Institutional responses for quality outcomes, Madison, Wi consin: Atwood Publishing.

Griffiths, G. (1998). The essence of structured systems analysis techniques. London; New York: Prentice Hall.

Griffiths, G., \& Lockyer, M. A. (1992). Structured methods and CASE tools. Video series, UK Department of Trade \& Industry.

IT\&P (2001). Special issue on action research in information systems. Information Technology \& People, 14(1).

B. H. Kahn (ed.) (1997). Web-based instruction. Englewood Cliffs, NJ: Educational Technology Publications.

Lockyer, M. A. \& Griffiths, G. (1989). ALSETT - Towards an educational IPSE, Software Engineering Journal, 4(4), $203-7$.

Lockyer, M. A. \& Hoggarth, G. (1996). CASE and methods guidance, Software Engineering Journal, 11(3), 141-7.

McKeachie, W. J. (1986). Teaching tips. Lexington, MA: D.C. Heath \& Co.

Robinson, B. \& Prior, M. (1995). Systems analysis techniques, London: Thomson.

Susman, G. I., \& Evered, R. D. (1978). An assessment of the scientific merits of action research. Administrative Science Quarterly, 23(December), 582-603.

Van Eynde, D., \& Bledsoe, J. (1990). The changing practice of organization development. Leadership and Organization Development Journal, 11(2), 25-39.

Wiley (2002). Web Site for Alan Dennis and Barbara Haley Wixom's Systems analysis \& design: An applied approach. http://wiley.com/college/info/dennis241008/resources/index.html

Yourdon, E. (1989). Modern structured analysis. Englewood Cliffs, N.J.: Yourdon Press/Prentice-Hall.

Zuber-Skerritt, O. (1992). Action research in higher education. London: Kogan Page.

Zuber-Skerritt, O. (Ed.). (1996). New directions in action research. London: Falmer. 


\section{Appendix: Student Evaluation Questionnaire}

\section{Teaching Materials}

1. Which teaching materials did you use? (tick all that apply)
Book
Videos
Web Site

2. Try to allocate a percentage to the amount you used each.
Book
Videos
Web Site

3. Why did you use the teaching materials that you did?

\section{Web Site}

4. Did you like the video clips?

5. Did you like the walkthroughs?

6. Did you find it easy to navigate the site?

7. Did you usually know what to do next from week to week or would you have liked a 'bookmark' on the site? (i.e. something that told you what you should be doing that week)

\section{Teaching Style}

8. Did you like the student centred approach or would you have preferred traditional lectures and tutorials?

9. What advantages did you think that there were to the student centred approach compared to traditional lectures and tutorials?

10. What disadvantages did you think that there were to the student centred approach compared to trad itional lectures and tutorials?

\section{General}

11. Any other comments about any of the teaching materials, the web site, the teaching style, the module, the module in relation to the course...?

\section{Biographies}

Gary Griffiths holds a BSc (Hons) in Computer Science and a PhD in Software Engineering. He is Head of Multimedia in the School of Computing \& Mathematics, University of Teesside. He has written a book and developed a video series on Structured Systems Analysis techniques. He worked full-time on a UK Government-funded project to spread good practice in teaching and learning, contributing to the development and dissemination of videos, $\mathrm{CDs}$ and a web site. His research interests include software process modelling, systems analysis techniques, flexible teaching and learning, and web engineering.

Briony J Oates holds a BA (Hons) in the humanities, an MSc in Information Technology, and a PhD in Information Systems. She is a Senior Lecturer in the School of Computing \& Mathema tics, University of Teesside, and a member of CIRA, Teesside University's Community Informatics Research and Applications Unit. Her research interests include the theory and practice of systems development and web development, research methods, teaching and learning, community informatics and e-democracy. 